INTRODUCTION

\title{
Space, place, and power in South African writing centres: Special issue in honour of Sharifa Daniels
}

\author{
Rose Richards $^{1}$ \\ Writing Lab, Language Centre, Stellenbosch University, South Africa \\ E-mail: rr2@sun.ac.za \\ Anne-Mari Lackay \\ Writing Lab, Language Centre, Stellenbosch University, South Africa \\ E-mail: amlackay@sun.ac.za \\ Selene Delport \\ Writing Lab, Language Centre, Stellenbosch University, South Africa \\ E-mail: selene@sun.ac.za
}

\begin{abstract}
A writing center cannot define itself as a space-we're often kicked out of our spaces. It's not a pedagogy. We're always re-articulating our pedagogy. It's certainly not an academic department. It crosses all disciplines. A writing center does not produce a text - the texts in writing centers are unfinished. And we don't own the texts our students create; those texts are cross-curricular, cross-linguistic, cross-discursive.
\end{abstract}

(Sunstein 1998: 8-9)

Keywords: space, place, power, writing centre, higher education, academic literacies

\section{Introduction}

This special issue is in honour of Sharifa Daniels' contribution to South African writing centre work and her part in the establishment of the Stellenbosch University Writing Lab (henceforth SU Writing Lab). The idea of a writing lab was the dream of Professor Leon de Stadler ${ }^{2}$ who visited American universities to research writing centres before starting the SU Writing Lab in 2001 as a project. Sharifa, Rose, and Anne-Mari were the founding staff members. From the humble beginnings of a shared office on the sixth floor of the Arts building and a borrowed

\footnotetext{
${ }^{1}$ Corresponding author.

${ }^{2}$ Leon de Stadler was the founder of the SU Writing Lab and the first director of the Language Centre (20032016). His fields of research are communication design and language planning.
} 
room on the fourth floor in the Social Work Department, we moved to a heritage building in Crozier Street in 2002. In 2003 we became part of Leon's newly constituted Language Centre. Selene joined the team a few years after this. We remained in Crozier Street right through to 2017, when part of the Language Centre moved to the premises of the old Methodist Centenary School in Banghoek Road. The move coincided with Sharifa's long-planned retirement and, in many ways, the SU Writing Lab appeared to have come to the end of an era.

We have put together this special issue to celebrate Sharifa's contribution to the South African writing centres movement, of which she was one of the founding members. In addition, Sharifa was one of the founding members of the Western Cape Writing Centres Forum. She has run national writing centre indabas ${ }^{3}$, has served on the board of the International Writing Centers Association (IWCA), and was a leader at the IWCA's Summer Institute. Her experiences and thinking have helped form and strengthen our movement over the course of nearly 20 years.

The relationship(s) of space, place, and power is a topic of much debate in writing centres. Writing centres worldwide have had to adapt their pedagogy to their surroundings in various ways and for different reasons. Reynolds (1998: 20) notes that "surroundings have an effect on learning or attitudes towards learning, and material spaces have a political edge [...] where writing instruction takes place has everything to do with how". In South Africa, this is no different and is perhaps made more complex by our troubled history, a theme with which Sharifa herself has grappled through the course of her career. While we have, in many ways, "borrowed" an American idea in implementing writing centres on our campuses, we have adapted this to our contexts.

The place-specific entanglements that South African writing centre practitioners experience have been explored to some extent in previous publications, most notably the collections edited by Archer and Richards (2011) and Clarence and Dison (2017). The articles in this special issue foreground the duality of South African writing centres firstly as physical spaces located on university campuses, and secondly as spaces in and through which pedagogical and institutional relationships of power play themselves out.

South African writing centres have emerged from an education system that was shaped by the country's politics and social structures (Archer and Richards 2011, Nichols 2011). Within this space, writing centres have tried to resist and challenge power structures in various ways, although sometimes we have had to work within these structures as well. Moreover, writing centres occupy a liminal space on many university campuses, and are seen as add-ins or addons to the main academic business of the university. These are themes that are close to the hearts of many South African writing centre practitioners, and hold a particular interest for Sharifa as we explain below. But first, we briefly outline some of the discussions around space, place, and power in writing centre work.

\section{Space, place and power in writing centre research}

As South Africans emerging from an education system that was (and sometimes still is) extremely inequitable, we know all too well the long shadow of our history and its impact on our present-day identities and spaces. Spaces and places are sites of struggle in our country and

\footnotetext{
${ }^{3}$ The word "indaba" comes from indigenous languages spoken in southern Africa, and means "a meeting to discuss a serious matter" (Collins Online English Dictionary 2019).
} 
are constantly being renegotiated. South African writing centre work is part of this struggle. In the 1970s and 80s, when historically-White tertiary institutions started accepting students of all races, it soon became apparent that more was needed than merely letting students into universities in order to overcome the legacy of apartheid education. By the late $80 \mathrm{~s}$, educationists were starting to move away from the deficit model to other ways of working with students from primarily disadvantaged backgrounds. These ways included those of genre theorists such as Kress (1982) and Cope and Kalantzis (1993), and theorists of explicit pedagogy such as Delpit (1995) and Archer and Richards (2011).

South African writing centres began to emerge around this period at the universities of the Western Cape (UWC), Cape Town (UCT), and the Witwatersrand (Wits). Writing centres may originally have been expected to be another remedial intervention, another peripheral place where disadvantaged students were sent to be "fixed". I (Rose) remember that this was the perception at Wits in the early 90s. However, in reality, South African writing centres were far more subversive than that, finding subtle ways of challenging this belief, often leveraging their peripheral status to do this. Working quietly on the peripheries at making the institutional boundaries more porous, writing centres trained students to work with other students in an individual way, to spread the types of literacy needed at university and sometimes to challenge these literacies, to help students rehearse their academic identities, and to strengthen their voices so that they could participate in university life.

As the landscape of South African higher education gradually changed to focus more on literacy as mastering a set of social practices, writing centres became more openly critical of the status quo and more willing to embrace anti-authoritarian ways of being. This has been a source of pride for many writing centres, but also a source of tension. After all, if one is hired to serve an institution, one cannot be too bold in criticising it. Carter (2009: 139) refers to this as "the writing centre paradox", and she develops this notion further in a critique of liberal democracy and the hegemonies it maintains. She argues that writing centres should attempt to keep both the tensions of the writing centre paradox alive without trying to resolve it, "in different rhetorical spaces for different rhetorical purposes" (Carter 2009: 150).

Another tension writing centres experience is that our historical and cultural heritage is in one place, South Africa, while a significant amount of our pedagogical heritage lies in another place, the US. American writing centres have long emphasised their role in social justice, transformation, and increasing access (Nichols 2017, Trimbur 2010). In her 2017 article, Nichols reminds us that non-directive tutoring (discussed in Brooks (2001) and Bruffee (2001)) and emphasising the writer over the writing (North 2008) are entrenched aspects of American writing centre work. She also makes the point that the Freedom Schools of the Civil Rights Movement, "through their use of open-ended dialogue offered, and still offer, important resources for democratic writing centres" (Nichols 2017: 184). One might also associate the less hierarchical peer-tutoring method with the South African version of the "each one teach one" movement.

Not everyone is comfortable with such a highly politicised approach to writing centre work. Even so, space, place, and power are and have always been contested ideas in writing centre literature. In his landmark article, North (2008) discusses the way in which writing centres are positioned in institutions, in terms of both literal and metaphorical space. In contrast to the marginal identity often imposed on writing centres, North (2008), Harris (1995), and others 
have defined writing centres as safe places that offer something unique to students, allowing them to develop themselves as well as their writing. Larsen (1979: 4) describes this as the "humanization" of a learning space.

\section{Space and place}

That "something unique" we refer to above extends to the experience of the people who work in writing centres. McKinney (2005) observes that, unlike other teaching staff who may teach in different locations, writing centre staff usually teach in a single space. This may account for the significance we invest in our space as well as the metaphors we use when speaking about it. We place a great deal of emphasis on writing centres being safe and non-institutional spaces (Harris 1995 and others). McKinney (2005: 65) lists a number of adjectives and metaphors that writing centre people like to apply to our spaces: "soft, calming, welcoming, comfortable, attractive, familiar, non-threatening, and friendly". She explains further that "[w]riting centers wanted to assure students that nothing harmful would be done to them upon entering - the centers were less doctor's office or science lab and more like any old living room" (McKinney 2005: 9). Writing centre practitioners would like to see our space as "a low-stakes space" (Singh-Corcoran and Emika 2011).

Writing centres have been described as liminal and defying spatial definition (Sunstein 1998: 9). These centres present different types of liminality and sometimes this can be generative (Petit 1997: 114). Cultural liminality has its advantages, for instance, it "allows students to think between their multiple cultures" (Sunstein 1998: 20, original emphasis). Harris (1995: 27-28) sees another type of in-betweenness: the writing centre "introduces into the educational setting a middle person, the tutor, who inhabits a world somewhere between student and teacher".

As writing centre practitioners, we tend to idealise our liminality. Severino (1994: 2) describes writing centres as "linguistic contact zones", "borderlands in which cultures and languages academic and non-academic - meet, meld, or mix [and] not only a site for the culture wars, but a site for the creation of contact literatures that result from languages and cultures in touch". This ideal is very appealing in post-apartheid South Africa where we have so much healing to do, and many South African writing centres have prided themselves on creating such spaces.

Despite our idealism, once we start critically examining writing centre space, it becomes apparent that our space is by no means value-neutral (Singh-Corcoran and Emika 2011). Instead of the idealised space we may prefer to imagine, writing centre space is complex and political (Reynolds 1998), partly due to our liminal positioning. It can be argued that the very idea of a writing centre, as originally conceived in some American universities, is very much a middleclass, Western idea born out of certain privileges (Singh-Corcoran and Emika 2011). South African writing centres have had to take this into account when designing their own space and inhabiting it. A call has been made to consider writing centres as "brave/r spaces" (Martini and Webster 2017). South African writing centres have had to be brave for as long as we have existed: many of our centres have been under-resourced in a way that would be difficult to imagine in the global North, we work with students who come from seriously deprived backgrounds and, despite excellent track records, some of our centres have had to fight decades' long battles for their survival. 
Writing centres are sites of various types of struggle (Petit 1997). Papay (2002), researching the UWC writing centre in the late 1990s, found that it offered safe spaces and comfort zones but also found that there was a need for a specific element of contact zone in order to challenge the status quo on campus. One way of doing this is to create the safe space. Another way is to use the space to rehearse academic identities and to help students negotiate their way through academic spaces (Grimm 2009). A third option is to use the writing consultation as a way of showing how academic texts function so that the student reader and writer can see the conflicts and context in which they study (Petit 1997).

As writing centre practitioners, we also need to remember that for students, writing centres may not have the same associations that they have for us. Some students might experience writing centres as "nonplaces" that are "marked by access rather than proximity" (Singh-Corcoran and Emika 2011). While this might be somewhat disappointing to writing centre practitioners for whom our space is so important, Augé (2000: 9) reminds us that nonplaces function in some ways as liminal spaces where people shed or lose an identity and find a new one. He adds that spaces' own identities can change, to be looked upon "as a place by some people and a nonplace by others, on a long-term or a short-term basis" (Augé 2000: 9).

Seeing the writing centre space as this complex type of space, one realises that, far from being marginal and a powerless handmaid of academia (Grimm 1996: 524), writing centres wield a very particular type of power. As in the US, South African writing centres are now present in almost every tertiary institution, and "are the single most common model for academic support" (Salem 2014: 37). More importantly, Salem explains that "[w]riting centers allow universities to signal the kind of literacy they sponsor, and they give universities a concrete venue for operationalizing institutional goals and agendas" (Salem 2014: 37). Sunstein (1998: 22) describes writing centres as "develop[ing] a lack of boundaries and grow[ing] with the metaphor of revision". This adaptability makes writing centres flexible spaces. Whatever our physical environment, writing centres need to be cognisant of the rhetorical spaces they occupy and create. This is crucial in South Africa where universities have committed to undoing the wrongs of decades of educational injustice.

\section{Power}

Being part of an institution has its challenges, and power structures tend to replicate themselves. The writing centre space is no different from any other space in that it reflects power structures, values, and access to resources of different sorts (Singh-Corcoran and Emika 2011, Ede 1996). Monty (2016) questions the grand narrative of writing centre work as creating a safe space for students and being liberatory, showing that instead of challenging power structures, this narrative might actually inadvertently re-entrench them. We need to be more critical of our spaces and our attitudes towards them (McKinney 2005: 19). She adds that when examining a space, one needs to consider who is constructing its identity.

Reynolds (1998: 33) calls for "a spatial politics of writing instruction" that would render our spaces - and perhaps our privilege - less transparent. She urges us as writing centre practitioners to "attend to the negotiations of power that take place and within a number of spaces: regional or topographical, domestic, situational, architectural or electronic, real" (Reynolds 1998: 13). This special issue is our contribution to that. 
North and Harris do, however, acknowledge that these places are often marginalised on campus. Traschel (1995) takes this further and shows how writing centre spaces are often feminised as spaces of care and that the safe space of the writing centre can be seen as powerless and marginal because of what it offers and how it offers it. One way that writing centres, both in South Africa and abroad, are marginalised and disempowered is through lack of funding. One hidden consequence of this is "a lack of time to reflect upon one's work" that can repress, and a lack of permanence that "can make it impossible to engage in meaningful work at all" (Ede 1996: 118). This is a way of regulating the handmaidens and ensuring that they do not rise above their station. Or, to put it another way, this is a variant of outsourcing care work to the feminised other while the "real" business of the university is funded, recognised, and rewarded.

Space, place, and power are inextricably entwined in writing centre work. And while many writing centre staff may view their own positions on campus and that of their writing centre as marginal, we nonetheless have certain types of power. We have the power of enacting institutional values (Ede 1996) and we usually have more power than the students who visit us. We need to question our own dogma, decisions, and complicity. If our places and spaces become too utopian and inflexible, we will become stuck in them. For us to do our jobs on campus - to help with redress and to alter the power differential - we need to keep our spaces as flexible as possible. We also need to ensure that we as writing centre practitioners continue to develop our rhetorical space, no matter how "in-between" it is, so that it reflects the values we uphold and that our voices can be added to institutional debates.

In the midst of establishing and maintaining our own roles and identities, we cannot afford to lose sight of our purpose: to help student writers unlock their own agency. That our students succeed at university is part of redressing the wrongs of the past, but we need to balance fitting into an institution with challenging and changing the institution. Here is where our power as writing centre practitioners lies. And this is why the idea of the contact zone was so appealing to Sharifa. We turn briefly now to discussing Sharifa's own background and her role in the South African writing centres network.

\section{Sharifa's contribution to South African writing centre work}

Where there are legacies of subordination, groups need places for healing and mutual recognition, safe houses in which to construct shared understandings, knowledges, claims on the world that they can then bring into the contact zone.

(Pratt 1991: 40)

The enmeshed themes of space, place, and power have been a focus of Sharifa's from before she established the SU Writing Lab with Anne-Mari and Rose in 2001. Rich (1986: 210) calls this "the politics of location". One of the ideas Sharifa often discussed with us was what type of a place a writing centre was supposed to be. For many years, writing centres were considered safe spaces for students in contrast to the often inhospitable institutions in which the centres were housed. An important point she made about post-apartheid education was that saying that the doors of learning shall be opened is one thing, but what happens after the student steps through those doors is quite another.

Sharifa explained that institutions are reflections of the power structures they serve and are often not safe spaces nor conducive to "non-traditional" students' wellbeing. She further 
pointed out that welcoming students to a place implies that the students do not belong there in the first place and are visitors. An institution should be willing to adjust to its students; the burden should not be on the students to change to fit in.

Sharifa's engagement with social issues began in her childhood, growing up in apartheid South Africa and watching her own community assailed by forced removals and other forms of injustice. She trained as a teacher and began working in secondary-school education during the 1970s. In the mid-80s, she received a scholarship to study in the US, and she spent two years at the University of Iowa where she received her Master's degree in Linguistics. While there, she worked in the university's writing centre where she was exposed for the first time to writing centre pedagogy. She returned to South Africa and later became the principal of Strand Secondary School in the Western Cape. During the last decades of apartheid, she witnessed first-hand the destructive effects of social injustice on the education system in which she worked. This strengthened her purpose of and commitment to challenging abuse of power and redressing social injustice. At the SU Writing Lab, years later, she had the opportunity to do exactly that.

During the 16 years that Sharifa worked at SU, she impacted many lives. She networked and collaborated to ensure that the SU Writing Lab was as accessible as possible to students. For instance, she was a driving force in making sure that the SU Writing Lab's services reached the Tygerberg and Bellville Park campuses ${ }^{4}$. Her networking and connections won us a consultation space in the Carnegie Research Commons ${ }^{5}$, and our relationship with the Commons has been mutually beneficial. She also supported working with Skype so that the distance-learning students could have access to the same resources as everyone else.

We began this section with a quote by Mary Louise Pratt, one of Sharifa's favourite theorists. Sharifa liked to use Pratt to explain her vision of writing centre space. Sharifa saw writing centres as one of the spaces on campus in which students could safely explore their ideas and identities. South African writing centres could be places of "healing and mutual recognition" (Pratt 1991: 40) where people of different cultures and identities could come together and experience each other as people first, learning from each other and contributing to each other's development beyond the writing centre (Hemmeter and Mee 1993). They could take their new insights away into the outside world and use them in the campus contact zones. In our context of post-apartheid South Africa, Sharifa also argued that sometimes a space that was too safe may not help students develop a better understanding of their context, and that sometimes a little less safety and a little more conflict might help students to reflect more on their own place in our rapidly changing society.

As Sharifa's colleagues, we often spoke with her about her experiences and about the social impact of education. She wanted people to empower themselves. She taught us to speak up and to challenge the status quo. She also had an indelible memory and an intimidating knowledge

\footnotetext{
${ }^{4}$ Stellenbosch University has a number of campuses: the Stellenbosch campus is based in the town of Stellenbosch, while the Tygerberg and Bellville Park campuses are based in the Northern Suburbs of Cape Town, about 45 minutes away from Stellenbosch.

5 The Carnegie Research Commons is located in the Stellenbosch University Library and is reserved for postgraduate students at master's and doctoral levels, as well as academic staff and researchers. It is equipped with comfortable working and meeting spaces, computers, and a collection of cutting-edge research texts to ensure that researchers feel supported (Stellenbosch University Library and Information Service 2017).
} 
of historical and social matters. There is a lot we could say about Sharifa's impact on our lives, but for the purposes of this introduction, we restrict ourselves to the following:

I (Anne-Mari) am very proud to say that Sharifa was my role model and mentor. She could address difficult and sensitive issues in a calm, objective and effective way, and could work collaboratively to find solutions that were fair and acceptable to all concerned. She was a special part of my support structure, encouraging me to further my education, and was a willing sounding board for me when I needed to discuss my educational options or any challenging situations in my work environment.

I (Selene) feel as if the SU Writing Lab raised me. A lot of what I learnt and how I exist in the world comes from my training at the Lab. I learnt from Sharifa that academic writing is no one's first language; if you have a clear sense of identity, no one can tell you who you are; and silent observation and listening deeply to what people are saying and how they are behaving is extremely powerful.

I (Rose) learned a great deal from Sharifa about diversity, equity, and equality, but particularly about creating a truly inclusive space in which all people could be welcomed. She got me involved in Brenda Leibowitz's Identity, Teaching and Learning project ${ }^{6}$, and I am truly thankful for this opportunity as it enabled me to develop, both as a researcher and a person, and indirectly led to my own doctoral research.

Sharifa's research has focused on educational biographies (2005), the student experience of writing centre pedagogy and feedback (2016), collaborations with departments (2017), and the pragmatics of language equity in the SU Writing Lab (2011, 2017). Recently, Sharifa edited a book with Rebecca Babcock entitled Writing centers and disability (2017) which examined an often neglected aspect of diversity in writing centre work. True to form, their book made sure to include the voices of not only disability researchers and writing centre directors, but also those of people actually living and working with disability, so that they could be the ones to share their own experiences and state their own needs.

\section{Articles, research notes, and Sharifa's interview in this special issue}

The articles that form the core of this special issue are all derived from research in South African universities, with the exception of Rebecca Babcock et al.'s article which is from the US. The South African articles draw on international writing centre scholarship, but also use South African writing centre and academic literacies scholarship. We hope that this scholarship will reach a wider audience through this special issue. The articles are arranged and grouped according to the following themes: writing centres, space, and place; writing centres and online spaces; writing centres and power; and writing consultants' agency.

The articles in the first section illustrate how the writing centre is a dialogic space in which students can develop their academic literacies in a collaborative way. A theme that runs throughout all three articles is how this dialogic space does away with the deficit model, making

\footnotetext{
${ }^{6}$ Brenda Leibowitz was an education activist who, at the time of her passing, was a Professor of Teaching and Learning at the University of Johannesburg. She set up the first South African writing centre at University of the Western Cape in the early 1990s. At the time of her largescale Identity, Teaching and Learning project at Stellenbosch University, she was the Director of the Centre for Teaching and Learning at this instituion.
} 
the writing centre space one of transformation. The first article by Puleng Sefalane-Nkohla and Thembinkosi Mtonjeni sets the tone for the section by showing that writing centres' collective battle, even today, is not to be seen as "fix-it shops" but rather as a "space with unique transformational pedagogies". The writing centre at the Cape Peninsula University of Technology (CPUT), where this study took place, faces unique challenges in this regard because the university itself is not focused on writing as learning but rather as a reporting tool. In their article, Karis Moxley and Arlene Archer show how creating a dialogic space can be used to support student writers with referencing and citation practices despite these practices being traditionally considered as undebatable. Halima Namakula and Maria Prozesky use an analysis of tutors' responses to an embedded academic literacies programme to argue that the intervention functions as a third space in which the students develop their knowledge and insight, and also contribute to altering the Discourse of their area of study.

We open the second section with our only non-South African contribution which is from Rebecca Babcock et al. at the University of Texas (Permian Basin). In this article, the authors verify Babcock's grounded theory model for writing consultations and find that the model is successful in one-to-one consultations at a writing centre but less so in the online space with asynchronous tutoring. The other two articles address the complexities of writing centres and the online environment. Karen Collett and Arona Dison focus on referencing and citation as a dialogic space in the online environment, while Robert Nanima addresses the unplanned use of online space during the \#FeesMustFall protests at UWC and the challenges this produced. This unplanned use of online space could be seen as an extension of the "crisis of location" that many contemporary writing centres experience (Singh-Corcoran and Emika 2011). At UWC, this took a particular form due to campus-wide disruptions.

The third section continues the theme of transformative practices in writing centres by specifically looking at how power is negotiated. Sherran Clarence contemplates the other side of creating a safe space for student writers - that of the risk involved in practising transformation and negotiating power relations within an institution. Pamela Nichols et al. reflect on how their writing-intensive programme at Wits University creates a horizontal power structure between the writing fellow and student writers, as well as between the writing fellows and the departmental lecturers. In that way, the power relationships are not only renegotiated between the consultant and consultee but also between the institution and the writing centre. In her article, Fatima Slemming traces her development from consultant to writing centre manager to social realism actor now broadening the collaborative community of the writing centre to include the larger institution.

The fourth section is written from the perspectives of previous writing consultants reflecting on their writing centre experiences and how these helped not only their respective consultees, but also their own development of agency. Emure Kadenge et al. focus on the collaborative nature of writing centre work by reflecting on how consulting within a particular discipline enhances not only the student's sense of agency but also their own, thus broadening the writing centre space to share our pedagogy beyond the writing centre. Janine Carlse, a former SU Writing Lab consultant, offers her insight into how the writing centre can share its implicit pedagogy with the larger institution by positing writing consultants as "critical friends" who advocate for student success but also facilitate the development of the student writer's agency. Collium Banda, a theologian and also a former SU Writing Lab consultant, focuses on 
mentoring as a tool to help both the consultant and consultee develop agency and promote life-long learning for both.

Some of the writing consultants whom Sharifa trained over the 16 years of her work at the SU Writing Lab have contributed to the issue with research notes reflecting on how their work with us has influenced the ways in which they think about teaching today. They are involved in different types of teaching and in a range of disciplines; nonetheless, their reflections pick up on the themes of transformation, agency, and identity formation touched upon in the previous articles. All of the writers reflect on how their writing centre experiences contribute to how they engage with their current students. They mention adaptability, active listening, and empathy as strategies they use not only to empower their students but as part of their own personal growth and identity formation. This emphasises Collium Banda's point that writing consultations pave the way for life-long learning - whether this is on the part of the consultant or that of the writer. It is heartening to think of the generations of consultants that have passed through the SU Writing Lab and out into the world, carrying the torch of our pedagogy with them.

The collection begins with Rebecca Babcock's interview with Sharifa about her work, and ends with a comic drawn by artist and former writing consultant, Neeske Alexander, about the SU Writing Lab looking towards a hopeful future. Special thanks go to Neeske for this comic and also for designing the cover of the special issue.

\section{Acknowledgements}

Our first acknowledgement goes to the authors of this special issue for their contributions in Sharifa's honour. We furthermore gratefully acknowledge our reviewers who gave generously of their time and expertise, and without whom this special issue could not have happened. We list the authors and the reviewers with their respective affiliations below.

Anjela Adamson (Stellenbosch University)

Andrea Alcock (Durban University of Technology)

Arlene Archer (University of Cape Town)

Rebecca Babcock (University of Texas Permian Basin)

Collium Banda (North West University)

Maud Bonato (Stellenbosch University)

Janine Carlse (Stellenbosch University)

Lewis Ckool (University of the Witwatersrand)

Sherran Clarence (Rhodes University)

Karen Collett (University of the Western Cape)

Sharifa Daniels (Stellenbosch University)

Aliethia Dean (University of Texas Permian Basin)

Selene Delport (Stellenbosch University)

Arona Dison (University of the Western Cape)

Laura Dison (University of the Witwatersrand)

Gerhardus Du Preez (Stellenbosch University)

Zimitri Erasmus (University of the Witwatersrand)

Victoria Hinesly (University of Texas Permian Basin)

Catherine Hutchings (University of Cape Town) 




\section{References}

Archer, A. and R. Richards. 2011. Writing centres as alternate pedagogical spaces. In A. Archer and R. Richards (eds.) Changing spaces: Writing centres and access to higher education. Stellenbosch: Sun Media. pp. 5-16.

Augé, M. 2000. Nonplaces. In A. Read (ed.) Architecturally speaking: Practicing art, architecture, and the everyday. New York: Routledge. pp. 7-12.

Babcock, R. and S. Daniels. 2017. Introduction. In R. Babcock and S. Daniels (eds.) Writing centers and disability. Southlake: Fountainhead Press. pp. 1-16.

Brooks, J. 2001. Minimalist tutoring: Making the student do all the work. In R.W. Barnett and J.S. Blummer (eds.) The Allyn and Bacon guide to writing center theory. Boston: Allyn and Bacon. pp. 219-224.

Bruffee, K. 2001. Peer tutoring and the 'conversation of mankind'. In R.W. Barnett and J.S. Blummer (eds.) The Allyn and Bacon guide to writing center theory. Boston: Allyn and Bacon. pp. 206-218.

Carter, S. 2009. The writing center paradox: Talk about legitimacy and the problem of institutional change. College Composition and Communication 61(1): 133-152. 
Clarence, S. and L. Dison. (eds.) 2017. Writing centres in higher education: Working in and across the disciplines. Stellenbosch: Sun Media.

Collins Online English Dictionary. 2019. Definition of 'indaba'. Available online: https://www.collinsdictionary.com/dictionary/english/indaba (Accessed 30 September 2019).

Cope, B. and M. Kalantzis. (eds.) 1993. The powers of literacy: A genre approach to teaching writing. London and Washington: Falmer Press.

Daniels, S. and D. Daniels. 2017. How inclusive is the Writing Lab environment to students with disabilities? Reflections from one South African university. In R. Babcock and S. Daniels (eds.) Writing centers and disability. Southlake: Fountainhead Press. pp. 305-323.

Daniels, S. and R. Richards. 2011. 'We're all in this thing together': An equitable and flexible approach to language diversity in the Stellenbosch University Writing Lab. In A. Archer and R. Richards (eds.) Changing spaces: Writing centres and access to higher education. Stellenbosch: Sun Media. pp. 33-44.

Daniels, S. and R. Richards. 2016. From autopsy to autonomy in writing centres: Postgraduate students' response to two forms of feedback in a health professions education module. Per Linguam 32(3): 48-59. https://doi.org/10.5785/32-3-644

Delpit, L. 1995. Other people's children: Cultural conflict in the classroom. New York: The New Press.

Ede, L. 1996. Writing centers and the politics of location: A response to Terrance Riley and Stephen M. North. The Writing Center Journal 16(2): 111-130.

Grimm, N.M. 1996. Rearticulating the work of the writing center. College Composition and Communication 47(4): 523-548. https://doi.org/10.2307/358600

Grimm, N.M. 2009. New conceptual frameworks for writing center work. The Writing Center Journal 29(2): 11-27.

Harris, M. 1995. Talking in the middle: Why writers need tutoring. College English 57(1): 23-42.

Hemmeter, T. and C. Mee. 1993. The writing center as ethnographic space. Writing Lab Newsletter 18(3): 4-5.

Kress, G. 1982. Learning to write. London: Routledge.

Larsen, R.B. 1979. A note on lab layout. Writing Lab Newsletter 3(6): 3-4.

Leibowitz, B., K. Booi, S. Daniels, A. Loots, R. Richards and I. van Deventer. 2005. The use of educational biographies to inform teaching and learning in an African university. South African Journal of Higher Education 19: 1220-1237. https://doi.org/10.4314/sajhe.v19i7. $\underline{50222}$ 
Martini, R.H. and T. Webster. 2017. Writing centres as brave/r spaces: A special issue introduction. The Peer Review 1(2). Available online: http://thepeerreview-iwca.org/issues/ braver-spaces/? (Accessed 27 September 2019).

McKinney, J.G. 2005. Leaving home sweet home: Towards critical readings of writing center spaces. The Writing Center Journal 25(2): 6-20.

Monty, R.W. 2016. The writing center as cultural and interdisciplinary contact zone. London: Palgrave Macmillan.

Nichols, P. 2011. A snowball in Africa with a chance of flourishing: Writing centres as shifters of power in a South African university. In A. Archer and R. Richards (eds.) Changing spaces: Writing centres and access to higher education. Stellenbosch: Sun Media. pp. 91-99. https://doi.org/10.1080/1013929x.1998.9678044

Nichols, P. 2017. 'Hopeful' directions for writing centres in South Africa: From safe spaces to transitional sites of articulating practice. Stellenbosch Papers in Linguistics Plus 53: 182-194. https://doi.org/10.5842/53-0-741

North, S. 2008. The idea of a writing center. In R.W. Barnett and J.S. Blumner (eds.) The Longman guide to writing center theory and practice. New York: Pearson Longman. pp. 63-78.

Papay, T.Y. 2002. Collaborating with a difference: How a South African writing center brings comfort to the contact zone. The Writing Center Journal 23(1): 5-22.

Petit, A. 1997. The writing center as 'purified space': Competing discourses and the dangers of definition. The Writing Center Journal 17(2): 111-122.

Pratt, M.L. 1991. Arts of the contact zone. Profession 91: 33-40.

Reynolds, N. 1998. Composition's imagined geographies: The politics of space in the frontier, city, and cyberspace. College Composition and Communication 50(1): 12-35. https://doi.org/ $\underline{10.2307 / 358350}$

Rich, A. 1986. Blood, bread and poetry: Selected prose 1979-1985. New York: W.W. Norton.

Salem, L. 2014. Opportunity and transformation: How writing centers are positioned in the political landscape of higher education in the United States. The Writing Center Journal 34(1): 15-43.

Severino, C. 1994. Writing centers as linguistic contact zones and borderlands. Writing Lab Newsletter 19(4): 1-5.

Singh-Corcoran, N. and A. Emika. 2011. Inhabiting the writing center: A critical review. Kairos: A Journal of Rhetoric, Technology and Pedagogy 16(3). Available online: http://www.technorhetoric.net/16.3/reviews/singh-corcoran_emika/introduction.html (Accessed 21 August 2019). 
Stellenbosch University Library and Information Service. 2017. Carnegie Research Commons: About. Available online: http://library.sun.ac.za/en-za/Research/rc/Pages/default.aspx (Accessed 30 September 2019).

Sunstein, B.S. 1998. Moveable feasts, liminal spaces: Writing centers and the state of inbetweenness. The Writing Center Journal 18(2): 7-26.

Traschel, M. 1995. Nurturant ethics and academic ideals: Convergence in the writing center. The Writing Center Journal 16(2): 24-45.

Trimbur, J. 2010. Multiliteracies, social futures, and writing centres. The Writing Center Journal 30(7): 88-91. 